\title{
Physical work load and gestational age at delivery
}

\author{
A P Koemeester, J P J Broersen, P E Treffers
}

\begin{abstract}
Objective-To assess the impact of physical activity on the gestational age at delivery in women performing physical tasks in their jobs during pregnancy. Methods-Qualified nurses at 15 weeks of pregnancy were asked through a questionnaire to describe the tasks in their regular job, the physical activities involved, and their exposure to other occupational stressors. The physical activities to be identified were walking, standing, lifting, stooping, squatting, and sitting.

Results-A high degree of daily physical work load during pregnancy seemed to be a significant predictor for the gestational age at delivery, whereas chemical and infectious agents were not.

Conclusions-Physical work load during pregnancy should be diminished to avoid adverse effects on gestational age at delivery.
\end{abstract}

(Occup Environ Med 1995;52:313-315)

Keywords: gestational age; physical work load; pregnancy

Gestational age is the most important factor that determines perinatal morbidity. In particular, a short duration of gestation is associated with serious neonatal and infant morbidity. ${ }^{1}$ The socioeconomic status of the population is a significant contributory factor to gestational age at delivery. ${ }^{2}$

Recently, several authors have reported that severe physical work load has an adverse influence on birthweight and gestational age at the time of delivery. ${ }^{2}$ In the Montreal survey, $\mathrm{McDonald}$ et al described associations between physically demanding occupations and both birthweight and gestational age. In a reanalysis of these data Armstrong et al clarified that work that involved heavy lifting, shift work, long working hours, or great fatigue did not reduce birthweight for gestational age but shortened the gestation period. ${ }^{4}$ After the publication of this report, other authors found that there was a relation between physical work load and such factors as the gestational age at delivery, ${ }^{56}$ the preterm birth rate, ${ }^{7-10}$ and complications due to preterm births. ${ }^{11}$

Since the $1980 \mathrm{~s}$, the employment rate of women of childbearing age has increased in the Netherlands to more than $50 \% .^{12}$ To investigate whether a guideline for a maximal permissible physical work load during pregnancy might be useful to prevent shortening of the gestational age at delivery, we studied the relation between physical work load and gestational age at time of delivery. The influence of socioeconomic status was minimised by selecting pregnant women from only one occupation.

\section{Subjects and methods}

Between August 1989 and May 1990 the management of 16 general hospitals were asked if they would join in the study. Twelve of them agreed. Each hospital was asked to send a written request to all their female qualified nurses between 21 and 46 years old who worked for two or more days a week. In this letter, the nurses were asked to fill in a reply form as soon as they knew that they were pregnant. This was to be done before 15 weeks of pregnancy. The nurses were taken into the study if they had worked through the first 12 weeks or longer of their pregnancy and if they were pregnant with a single fetus. A total of 116 nurses were entered into the study.

At 15 weeks of pregnancy we sent the nurses their first questionnaire. With examples of nine tasks, they were asked to list the usual tasks in their job before they became pregnant-that is, those done at least twice a week, the physical activities involved, and the duration of those tasks. The physical activities to be identified were walking, standing, lifting, stooping, squatting, and sitting. Besides their physical work load, the nurses were asked for data on age, smoking, drinking alcohol, parity, size of the family, number of sporting activities, number of working hours, work schedule, pressures on time, amount of freedom in job, and exposure to noise, chemicals, and infectious agents in the workplace. Exposure to ionising radiation was not likely to occur.

At 20 weeks of pregnancy, they were asked during an interview for ergonomic details and the frequency of their physical activities a day. Furthermore, the nurses were asked to fill in a short questionnaire about health problems when they stopped work completely. The midwife or obstetrician was asked to send us, after delivery, their prenatal records and a determination of the gestational age by ultrasound scan if this was done. In $80 \%$ of the nurses gestational age was determined by ultrasound scan. In the remaining $20 \%$ it was computed based on the first day of the last menstrual period. 
Table 1 Percentage of subjects doing a task that had to lift, stoop, or squat as well as walk and stand without time to sit (tasks with a high physical work load are printed bold)

\begin{tabular}{|c|c|c|c|}
\hline Tast & $\begin{array}{l}\text { Typical combination } \\
\text { of physical activities }\end{array}$ & $\begin{array}{l}\text { Subjects } \\
\text { doing } \\
\text { the task (n) }\end{array}$ & $\begin{array}{l}\text { Lifting } \\
\text { or stooping } \\
\text { in combination } \\
\text { with walking } \\
\text { and standing } \\
\text { without time } \\
\text { to sit (\%) }\end{array}$ \\
\hline $\begin{array}{l}\text { Care of patients in bed } \\
\text { Replenishing stocks } \\
\text { Cleaning up } \\
\text { Administration of } \\
\text { medicines and checking }\end{array}$ & $\begin{array}{l}\text { WA + ST + LI + STO/SQ } \\
\text { WA + LI+STO/SQ } \\
\text { WA + ST + (LI or STO/SQ })\end{array}$ & $\begin{array}{r}99 \\
83 \\
100\end{array}$ & $\begin{array}{l}87 \\
67 \\
64\end{array}$ \\
\hline of patients & WA + ST+ STO/SQ & 105 & 45 \\
\hline $\begin{array}{l}\text { Distributing meals } \\
\text { Transport of patients }\end{array}$ & $\mathrm{WA}+\mathrm{ST}+\mathrm{SI}+\mathrm{LI}+\mathrm{STO} / \mathrm{SQ}$ & 78 & 42 \\
\hline $\begin{array}{l}\text { Transport of patients } \\
\text { Receiving new patients }\end{array}$ & $\begin{array}{l}\text { WA }+(\mathrm{LI} \text { or } \mathrm{STO} / \mathrm{SQ}) \\
\text { WA + SI }\end{array}$ & $\begin{array}{l}89 \\
87\end{array}$ & 24 \\
\hline $\begin{array}{l}\text { Receiving new patients } \\
\text { Giving assistance }\end{array}$ & $\begin{array}{l}\text { WA+SI } \\
\text { WA +ST }\end{array}$ & $\begin{array}{l}87 \\
93\end{array}$ & 11 \\
\hline Keeping records & SI & 37 & $\begin{array}{l}8 \\
3\end{array}$ \\
\hline Talking about patients & SI & 105 & 0 \\
\hline Taking a break & SI & 114 & 0 \\
\hline
\end{tabular}

WA = walking, $S T=$ standing, $\mathrm{LI}=$ lifting, $S T O=$ stopping, $S Q=$ squatting, $S I=$ sitting.

EXPOSURE ASSESSMENT

According to a typical combination of physical activities, we classified 11 tasks (table 1). For each task we computed the percentage of subjects who had to lift, stoop, or squat in combination with walking and standing without having time to sit. We considered that this combination of physical activities contained the highest degree of physical work load. Tasks in which about two thirds or more of the nurses carried out this combination of physical activities were classified as having a high physical work load (table 1).

With each subject the daily duration of the job tasks with a high physical work load was computed. To investigate the effect on gestational age at delivery, we used the daily duration of the tasks with a high physical work load as a quantitative measure. Besides this combination of physical factors, the influence of single physical factors was investigated. For lifting and stooping the frequency per day was used and for standing the duration per day.

STATISTICAL ANALYSIS

Predictors of the gestational age at delivery were traced by a stepwise multiple regression procedure, in which all variables are kept in
Table 2 Mean gestational age (SEM) by duration of high physical work load $(n=116)$

\begin{tabular}{lll}
\hline $\begin{array}{l}\text { Duration of physical } \\
\text { work load }(h)\end{array}$ & $\begin{array}{l}\text { Mean (SEM) } \\
\text { gestational age } \\
\text { at delivery (days) }\end{array}$ & Subjects (n) \\
\hline $0-1$ & $287(7)$ & 11 \\
$1-2$ & $282(9)$ & 33 \\
$2-3$ & $277(18)$ & 40 \\
$3-4$ & $278(7)$ & 24 \\
$4-5$ & $265(45)$ & 5 \\
$5-6$ & -- & 0 \\
$6-7$ & $269-$ & 1 \\
$7-8$ & $269(23)$ & 2 \\
\hline
\end{tabular}

the model when new variables are added. The dose-response relation between physical work load and gestational age at delivery was tested by analysis of variance. The relation between high risk during pregnancy and gestational age at delivery was investigated by the $t$ test. A P value of $<0.05$ was considered to be significant.

\section{Results}

Care of patients in bed, cleaning up, and replenishing stocks were found to be tasks with a high physical work load, and the other tasks-such as keeping records, assisting at medical investigations, distributing meals etc-were regarded as of low physical work load. Almost two thirds of all nurses performed tasks with a high physical work load (table 2) for more than two hours a day.

The nurses were classified into groups according to the duration of tasks with a high physical work load (less than two hours, two to four hours, four hours or more) and a significant difference in gestational age at delivery was found between the groups (analysis of variance $F(2113)=4.73, \mathrm{P}=0.01$, table 2$)$.

To assess whether other risks during pregnancy could explain the results, we investigated the relation between gestational age at delivery and an indication in early pregnancy of the need for specialist care in hospital during delivery. Because of the significance of this relation ( $P=0.02, t$ test), we excluded these nurses from further analysis $(n=46)$.

Stepwise multiple regression analysis on the

Table 3 Multiple correlation coefficient $(R)$, explained variance $\left(R^{2}\right)$, slope $(B)$ and significance $(P)$ after stepwise multiple regression with non-occupational and occupational factors for gestational age at delivery in the group of subjects without extra risk during pregnancy $(n=70)$

\begin{tabular}{|c|c|c|c|c|}
\hline Steps and variables & $\boldsymbol{R}$ & $R^{2}$ & $B$ & $P$ \\
\hline $\begin{array}{l}\text { Step } 1 \text { non-occupational factors: } \\
\text { Smoking } \\
\text { Drinking } \\
\text { Parity } \\
\text { Age } \\
\text { Sporting activities } \\
\text { Step } 2 \text { non-physical occupational factors. }\end{array}$ & 0.22 & 0.05 & $\begin{array}{r}0.15 \\
0.11 \\
-0.43 \\
0.16 \\
-0.09\end{array}$ & $\begin{array}{l}0 \cdot 35 \\
0 \cdot 47 \\
0 \cdot 06 \\
0 \cdot 29 \\
0 \cdot 48\end{array}$ \\
\hline $\begin{array}{l}\text { Step } 2 \text { non-physical occupational factors: } \\
\text { Job decision latitude } \\
\text { Time pressures } \\
\text { Night work } \\
\text { Noise } \\
\text { Chemical agents } \\
\text { Infectious agents } \\
\text { Step } 3 \text { Work (h/week) }\end{array}$ & 0.27 & 0.07 & $\begin{array}{r}0.02 \\
0.22 \\
0.01 \\
0.07 \\
-0.04 \\
-0.06 \\
-0.11\end{array}$ & $\begin{array}{l}0.88 \\
0 \cdot 12 \\
0.97 \\
0.61 \\
0.80 \\
0.67 \\
0.52\end{array}$ \\
\hline $\begin{array}{l}\text { Step } 4 \text { physical activities: } \\
\text { Frequency of stooping per day } \\
\text { Frequency of lifting per day } \\
\text { Frequency of standing per day } \\
\text { Step } 5 \text { duration of tasks }\end{array}$ & $\begin{array}{l}0.28 \\
0.33\end{array}$ & $\begin{array}{l}0.08 \\
0.11\end{array}$ & $\begin{array}{r}-0 \cdot 11 \\
-0.02 \\
0 \cdot 24 \\
0 \cdot 10\end{array}$ & $\begin{array}{l}0.52 \\
0.86 \\
0 \cdot 12 \\
0.53\end{array}$ \\
\hline with physical work load & 0.49 & $0 \cdot 24$ & -0.49 & 0.004 \\
\hline
\end{tabular}


Table 4 Distribution of subjects by exposure to tobacco $(n=70)$

\begin{tabular}{ll}
\hline $\begin{array}{l}\text { Cigarettes/day } \\
(n)\end{array}$ & $\begin{array}{l}\text { Subjects } \\
(\%)\end{array}$ \\
\hline 0 & 83 \\
$1-10$ & 13 \\
$\geqslant 10$ & 4 \\
\hline
\end{tabular}

Table 5 Distribution of subjects by exposure to alcohol $(n=70)$

\begin{tabular}{ll}
\hline $\begin{array}{l}\text { Glasses of } \\
\text { alcohol/week } \\
(n)\end{array}$ & $\begin{array}{l}\text { Subjects } \\
(\%)\end{array}$ \\
\hline 0 & 79 \\
$1-5$ & 20 \\
$\geqslant 5$ & 1 \\
\hline
\end{tabular}

group of nurses without extra risks during pregnancy showed that the daily duration of tasks with a high physical work load was significantly correlated with a shorter gestational age at delivery (table $3, P=0.004$ ). None of the specific physical factors contributed significantly. The explained variance increased in the stepwise regression after addition of specific physical factors from $R^{2}=0.08$ to $R^{2}=$ $0 \cdot 11$ and after addition of the duration of the physical work load per day from $R^{2}=0.11$ to $R^{2}=0 \cdot 24$.

In this selected population of nurses with a normal course of pregnancy $17 \%$ were exposed to tobacco and $21 \%$ to alcohol (table 4 and 5). Smoking and alcohol were not related to gestational age at delivery. None of the other non-occupational factors significantly influenced gestational age at delivery (table 3).

\section{Discussion}

In this study we gathered our data through questionnaires and an interview. It is likely that nurses in a poor physical condition were more disposed to call their tasks aggravating than those in a better state, and that they might have a shorter gestational age at delivery. It should be noted, however, that we did not solicit complaints: we asked only for information about the types of tasks, physical activities involved, and the duration of those tasks.

Our self reported data were subjective, although we attempted to minimise the misclassification of the physical work load in nurses' work. Independent of the answers given, we classified all tasks by increasing physical work load. This made our classification less dependent on subjective perceptions and judgements. By collecting the data in early pregnancy, recall bias was avoided.

The study population was relatively uniform in socioeconomic status. As some managerial nurses were included, there may have been some variation in socioeconomic status, but this could only be slight.

We detected a significant relation between the duration of high physical work load per day and gestational age at delivery in a group of nurses with totally normal pregnancies. This suggests that high physical work load should be reduced during pregnancy. The differences in mean gestational age at delivery between the three groups (less than two hours, two to four hours and four hours or more) suggest that the duration of high physical work load of pregnant nurses should be limited to no more than two hours a day.

In this study, tasks with a high physical work load were defined as having a combination of walking, standing, lifting, stooping, and squatting without sitting. The duration of these tasks was significantly correlated with gestational age at delivery, whereas specific physical factors were not. This means that especially this combination of physical activities should be substantially reduced, and so the gestational age at delivery should increase. Probably several, rather than one specific physical factor, are responsible for the adverse effects of physical work load on gestational age at delivery. Moreover, every study of gestational age at delivery and of preterm birth should always include information about the sort and degree of physical work load of the women during pregnancy.

Surprisingly, risk factors like smoking and alcohol consumption did not cause differences in gestational age at delivery in this study. This might be explained by the low prevalence of these habits in the studied population.

1 Veen S, Ens-Dokkum MH, Schreuder AM, VerlooveVanhorick SP, Brand R, Ruys JH. Impairments, disabilities, and handicaps of very preterm and very low birthweight infants at 5 years of age. Lancet 1991;338

2 Marbury MC. Relationship of ergonomic stressors to birthweight and gestational age. Scand $\mathcal{f}$ Work Environ Health 1992;18:73-83.

3 McDonald AD, McDonald JC, Armstrong BG, Cherry NM, Nolin AD, Robert D. Prematurity and work in pregnancy. Br f Ind Med 1988;45:56-62.

4 Armstrong BG, Nolin AD, McDonald AD. Work in pregnancy and birth weight for gestational age. $\mathrm{Br} \mathcal{F}$ Ind $\mathrm{Med}$ 1989;46:196-9.

5 Barnes DL, Adair LS, Popkin BM. Women's physical activity and pregnancy outcome: a longitudinal analysis from the Philippines. F Epidemiol 1991;20:162-72.

6 Nurminen T, Lusa S, Ilmarinen J, Kurppa K. Physical work load, fetal development and course of pregnancy. Scand f Work Environ Health 1989;15:404-14.

7 Ramirez G, Grimes RM, Annegers JF, Davis BR, Slater $\mathrm{CH}$. Occupational physical activity and other risk factors for preterm birth among US Army primigravidas. $A m \mathcal{F}$ for preterm birth among US A
Public Health 1990;80:728-30.

8 Teitelman AM, Welch LS, Hellenbrand KG, Bracken MB. Effect of maternal work activity on preterm birth and low birth weight. $f$ Epidemiol 1990;131:104-13.

9 Ahlborg G, Bodin L, Hogstedt C. Heavy lifting during pregnancy - A hazard to the fetus? A prospective study. Int $f$ Epidemiol 1990;19:90-7.

10 Homer CJ, Beresford SAA, James SA, Siegel E, Wilcox S. Work-related physical exertion and risk of preterm, low birthweight delivery. Paediatr Perinatal Epidemiol 1990;4 161-74.

11 Magann EF, Nolan TE. Outcome in an active-duty population. Obstet Gynecol 1991;78:391-3.

12 Emancipatiebeleid in macro-economisch perspektief. Den Haag: Emancipatieraad, 1989. 